\title{
Clinical features and prognostic factors of male breast cancer vs. female breast cancer
}

\author{
Guo Sang ${ }^{1,2}$, Hong Pan ${ }^{1}$, Chen Lu$^{2}$, Rongneng Sun ${ }^{2}$, Xiaoming Zha ${ }^{1}$, Shui Wang ${ }^{1}$, Dongya Zhu ${ }^{3}$ \\ ${ }^{1}$ Department of Breast Surgery, the First Affiliated Hospital of Nanjing Medical University, Nanjing, China; ${ }^{2}$ Department of Thyroid and Breast \\ Surgery, Wuhu Second People's Hospital, Wuhu, China; ${ }^{3}$ School of Pharmacy, Nanjing Medical University, Nanjing, China \\ Contributions: (I) Conception and design: G Sang, H Pan, C Lu, S Wang, D Zhu; (II) Administrative support: S Wang, D Zhu; (III) Provision of \\ study materials or patients: H Pan, C Lu, S Wang; (IV) Collection and assembly of data: G Sang, H Pan, C Lu, R Sun, X Zha, S Wang; (V) Data \\ analysis and interpretation: G Sang, H Pan, C Lu, R Sun, X Zha, S Wang; (VI) Manuscript writing: All authors; (VII) Final approval of manuscript: \\ All authors. \\ Correspondence to: Dr. Dongya Zhu. School of Pharmacy, Nanjing Medical University, 818 Tianyuan East Road, Nanjing 211166 , China. \\ Email: dyzhu@njmu.edu.cn; Dr. Shui Wang. Department of Breast Surgery, the First Affiliated Hospital of Nanjing Medical University, 300 \\ Guangzhou Road, Nanjing 210029, China. Email: ws0801@hotmail.com.
}

Background: To investigate the clinicopathological features and prognostic factors of male breast cancer (MBC) and female breast cancer (FBC) patients.

Methods: A total of $90 \mathrm{MBC}$ and $180 \mathrm{FBC}$ patients were included in this retrospective study. The clinicopathological features, disease-free survival rate (DFSR), and overall survival rate (OSR) were compared between the two groups. Cox proportional hazard model was used to analyze the factors affecting the survival rates.

Results: Most MBC were invasive ductal carcinoma (70/90, 77.8\%) and luminal type (83/90, 92.2\%), and were treated with modified radical mastectomy (78/90, 86.7\%). Compared with women, there were more patients with one-set age of $\geq 70$ years old, having family history of cancer, comorbid with underlying diseases in the male patients. They also had higher portion of patients at T3 and T4 stages. The rates of male patients receiving adjuvant radiotherapy, chemotherapy and endocrine therapy were lower $(\mathrm{P}<0.05)$ than female patients. OSR and DFSR were lower in the male patients than in the female patients $(\mathrm{P}<0.05)$. $\mathrm{T}$ stage, TNM stage, the status of progesterone receptor and endocrine therapy were independent prognostic factors for survival of $M B C(\mathrm{P}<0.05)$; TNM stage, chemotherapy or endocrine therapy were independent factors for survival of FBC $(\mathrm{P}<0.05)$.

Conclusions: Compared with FBC, MBC occurs later with more underlying diseases and lower survival rates. $\mathrm{MBC}$ is less active in adjuvant therapy and endocrine therapy. Since MBC has more luminal type, increased endocrine therapy may improve the survival.

Keywords: Breast cancer; clinicopathological feature; prognosis; TNM stage

Submitted Jan 13, 2021. Accepted for publication Mar 25, 2021.

doi: $10.21037 /$ tcr-21-1

View this article at: http://dx.doi.org/10.21037/tcr-21-1

\section{Introduction}

In the United States, 271,270 new breast cancers (BC) occur each year, accounting for about $15 \%$ all new malignant tumors, among them 42,260 patients died of BC (1). In China, over 42,000 cases of BC were diagnosed, among them 70,700 patients died of BC $(2,3)$. Compared with female breast cancer (FBC), male breast cancer (MBC) is relatively rare, accounting for less than $1 \%$ of all $\mathrm{BC}$ and $1 \%$ of all cancers in males (4), but the number of $\mathrm{MBC}$ has been rising gradually $(1,5,6)$. Previously, most studies on BC were 
conducted on FBC while MBC is less addressed. Because of the lack of guidelines and research data, the diagnosis and treatment of $\mathrm{MBC}$ have mainly relied on adopting clinical practices developed to treat female BC patients (7). However, it is generally agreed that there are considerable differences in survival rates and clinicopathological features between MBC and FBC (8-10). For example, MBC has its unique clinical features such as nipple ulcer and discharge with blood (11), advanced one-set age (12), high positive rate of estrogen receptor (ER) as compared with FBC (13). In addition, the prognosis with regard to the expression of ER is different between FBC and MBC (14). Therefore, it might be unreasonable to follow the treatment strategies for FBC to treat MBC. While extensive studies have been conducted with FBC regarding its clinical feature and risk factors (15-17) and many factors have been identified to be significant prognostic factors such as neutrophil to lymphocyte ratio (18), myeloperoxidase-positive neutrophil (19), expression of FGD3 gene (20), in addition to histological grade $(21,22)$, relatively less is known about MBC. According to a single-center study, ER, progesterone receptor (PR) and human epidermal growth factor receptor 2 (HER-2) were found to have predictive value for survival of MBC, and age, TNM stage and histological grade of tumor may affect the prognosis of MBC $(23,24)$. However, these studies were conducted with relatively small samples, and the conclusions have not been validated in large and different populations. Recently, nomograms that predict $\mathrm{BC}$-specific survival for $\mathrm{MBC}$ have been developed to assist the diagnosis and treatment of MBC. These nomograms are based on data from the Surveillance, Epidemiology, and End Results (SEER) database with large sample size, and indicate that the 3- and 5-year decision curve analysis curves could yield larger net benefits than the traditional American Joint Committee on Cancer (AJCC) stage (25). Clinically, $\mathrm{MBC}$ is different from $\mathrm{FBC}$ in a number of aspects, such as the biological characteristics, hormone levels, and risk factors $(26,27)$ and is less characterized for optimal treatment and management.

To better understand the clinicopathological feature and factors affecting the prognosis of $\mathrm{MBC}$, we conducted this study retrospective analysis. The findings may help improve the diagnosis and treatment of MBC. We present the following article in accordance with the STROBE reporting checklist (available at http://dx.doi.org/10.21037/tcr-21-1).

\section{Methods}

\section{Patients}

This was a retrospective study. A total of 90 male patients diagnosed with BC between January 1, 2008 and December 31, 2014 at our centers were included in this study. Female patients were randomly drawn from a pool of $1,869 \mathrm{FBC}$ patients. All patients were diagnosed by pathological analysis of biopsy or surgical samples. Patients were excluded if they did not have complete follow-up data and had other tumors. Demographic and clinical data were retrieved from the hospital databases, which include gender, age, menstrual status, clinical stage, type of surgery, tumour site, tumour type, grade, pathological stage, underlying diseases and family history of cancer. This study was approved by the Ethics Committee of Nanjing Medical University (approval No.: NMU 2719-3), conducted in accordance with the Declaration of Helsinki (as revised in 2013) and written informed consent was obtained from every participant.

\section{Pathological diagnosis and staging}

Pathological and immunohistochemical analyses were performed by two pathologists blinded to the patient information. Hematoxylin and eosin (HE) staining was used for histochemical analysis. The expressions of ER, PR and HER-2 were detected immunohistochemically by monoclonal antibodies against ER (1:500, cat. no. ss-121), PR (1:100, cat. no. as-221) and HER-2 (1:500, cat. no. es321) using commercial kits from Mbiotech, Wuhan, China, according to the manufacture's protocols. Cancer staging and molecular subtyping based on the expression of ER, PR, HER-2 and Ki-67 (cat. no. ks-212) were carried out according to the 8th edition of AJCC staging manual (28) and the United States National Comprehensive Cancer Network guidelines (29). Distant metastasis was diagnosed and confirmed by biopsy of the primary and metastatic lesions. Computed tomography (CT), B-ultrasound and whole-body bone scan (WBS) were performed to confirm the staging.

\section{Treatments}

For male patients, modified radical mastectomy was performed with axillary lymph node dissection or sentinel 
node biopsy as described previously $(30,31)$. Adjuvant radiotherapy was given with a dose of $50 \mathrm{~Gy} / 25 \mathrm{~F}$ and classical CMF regimen [cyclophosphamide (C) days 1-14 with intravenous methotrexate $(\mathrm{M})$ and fluorouracil $(\mathrm{F})$ on days 1 and 8, repeated every 28 days] or ACT regimen (adriamycin, cyclophosphamide and taxol) was applied. Endocrine therapy was performed with tamoxifen, letrozole, or castration plus letrozole.

For female patients, both modified radical mastectomy and breast-conserving surgery were performed. In addition, the same adjuvant radiotherapy, CMF, ACT and endocrine therapy were used following surgery. For some patients, AC-TH regimen (adriamycin, cyclophosphamide, taxol and trastuzumab) were given.

\section{Follow-ups}

The follow-up time in this study was defined as the time between the date of diagnosis to December 31, 2018. Follow-up was made through inpatient visits, outpatient visits and phone interview if the patients did not make hospital visit. During the follow-up, data regarding patient's treatment, examinations and survival status were collected. Disease-free survival was defined as the time between the date of diagnosis to the recurrence of the disease, overall survival was defined as the time between the date of diagnosis to death or the last follow-up.

\section{Statistical analysis}

The data were analyzed using SPSS version 11.5 for Windows (SPSS Inc., Chicago, IL, USA). The normality of distribution of continuous variables was tested by onesample Kolmogorov-Smirnov test. Continuous variables with normal distribution were presented as mean [standard deviation (SD)]; non-normal variables were reported as median [interquartile range (IQR)]. Means of 2 continuous normally distributed variables were compared by independent samples Student's $t$-test. The frequencies of categorical variables were compared using Pearson $\chi^{2}$ or Fisher's exact test, when appropriate. Survival was estimated by the Kaplan-Meier method. The hazard ratio (HR) was estimated using a Cox proportional hazards regression model. A value of $\mathrm{P}<0.05$ was considered significant.

\section{Results}

\section{Patient clinical characteristics}

The median age of male patients was significantly older than that of female patients [61 (33.0-86.0) vs. 46.6 (24.0$81.0)$ years, $\mathrm{P}<0.05]$. The median follow-up times were 58.3 (5.0-96.0) and 63.5 (8.0-96.0) months for male and female patients, respectively. While the most of the patients were Han nationality, there were 48 being ethnic minorities, including 8 Uygur (3 male, 5 female), 9 Kazak (2 male and 7 female), 31 Mongolian (7 male, 24 female). For male patients, 27 (30\%) had family history of cancer, among them 13 were BC, 32 had underlying diseases, including cardiovascular diseases, chronic renal insufficiency, and more than two of the three diseases (kidney disease, hypertension and coronary heart disease). For female patients, there were 16 cases with family history of cancer, among them 8 were BC; 6 case with underlying disease (coronary atherosclerotic heart disease). The percentages of male patients with family history of cancer and underlying diseases were significantly higher than female patients $(\mathrm{P}<0.05)$. The marital status was similarly between the two groups with about $90 \%$ being married.

For MBC, based on T staging, there were $9 \mathrm{~T} 1,13 \mathrm{~T} 2$, $32 \mathrm{~T} 3$ and $36 \mathrm{~T} 4$ patients; based on TNM staging, there were 22 I, 34 II, 14 III and 20 IV patients. Among the IV $\mathrm{BC}$, there were 13 lung metastases, 4 bone metastasis and 2 liver metastases. Molecular subtyping showed that 46 cases were positive for ER, 42 positive for $\mathrm{PR}$ and 4 positive for HER-2. Twelve percent of them were Ki- $67 \geq 14 \%$. For female patients, there were 42 Tis, $40 \mathrm{~T} 1,22 \mathrm{~T} 2,38 \mathrm{~T} 3$ and $38 \mathrm{~T} 4 \mathrm{BC}$ and were 60 0, 42 I, $40 \mathrm{II}, 20 \mathrm{III}$ and $18 \mathrm{IV}$ BC. Among the IV BC, there were 12 lung metastasis, 4 bone metastasis and 2 liver metastases. Molecular subtyping showed that 112 cases were $\mathrm{ER}^{+}, 64 \mathrm{PR}^{+}$and $32 \mathrm{HER}-2^{+}$. Fourteen percent of them were Ki-67 $\geq 14 \%$. Patients with luminal cancer were more in MBC than in FBC $(92.2 \%$ vs. $61.1 \%, \mathrm{P}<0.001)$, while there were more basal-like $\mathrm{BC}$ in female than in male $(17.8 \%$ vs. $3.3 \%, \mathrm{P}<0.001$, Table 1$)$.

Compared with females, the percentages of male patients with onset time $\geq 70$ years old, family history of cancer, underlying diseases, T3 and T4 stages, invasive ductal carcinoma and luminal type were significantly higher (all $\mathrm{P}<0.05)$, while other clinical data were similar between 
Table 1 Demographic and clinicopathological characteristics of breast cancer patients

\begin{tabular}{|c|c|c|c|c|}
\hline Characteristics & Male $(n=90)$ & Female $(n=180)$ & $\chi^{2}$ & $\mathrm{P}$ \\
\hline Han & $78(86.7)$ & $144(80.0)$ & & \\
\hline Minority & $12(13.3)$ & $36(20.0)$ & & \\
\hline Age (year), n (\%) & & & 18.762 & $<0.001$ \\
\hline$\geq 70$ & $58(64.4)$ & $56(31.1)$ & & \\
\hline Marital status, n (\%) & & & 0.712 & 0.196 \\
\hline Married & $82(91.1)$ & $162(90.0)$ & & \\
\hline Unmarried & $5(5.6)$ & $6(3.3)$ & & \\
\hline Underlying disease, n (\%) & $32(35.6)$ & $6(3.3)$ & 32.467 & $<0.001$ \\
\hline Mass position, n (\%) & & & 1.443 & 0.215 \\
\hline Right & $41(45.6)$ & $102(56.7)$ & & \\
\hline Left & $49(54.4)$ & $78(43.3)$ & & \\
\hline \multicolumn{5}{|l|}{ Tumor type, n (\%) } \\
\hline Carcinoma in situ & $3(3.3)$ & $44(24.4)$ & 5.016 & 0.025 \\
\hline Invasive ductal carcinoma & $70(77.8)$ & $110(61.1)$ & 8.035 & 0.007 \\
\hline Invasive lobular carcinoma & $7(7.8)$ & $14(7.8)$ & 1.581 & 0.358 \\
\hline $\mathrm{N}$ stage, $\mathrm{n}(\%)$ & & & 2.507 & 0.164 \\
\hline No & $38(42.2)$ & $82(45.6)$ & & \\
\hline Yes & $52(57.8)$ & $98(54.4)$ & & \\
\hline TNM stage, n (\%) & & & 3.271 & 0.072 \\
\hline $0+1+I I$ & $56(62.2)$ & $142(78.9)$ & & \\
\hline III + IV & $34(37.8)$ & $38(21.1)$ & & \\
\hline \multicolumn{5}{|l|}{ Molecular type, n (\%) } \\
\hline Luminal (A + B) & $83(92.2)$ & $110(61.1)$ & 14.286 & $<0.001$ \\
\hline HER-2 ${ }^{+}$ & $4(4.4)$ & $38(21.1)$ & 18.322 & $<0.001$ \\
\hline Basal-like breast cancer & $3(3.3)$ & $32(17.8)$ & 10.201 & 0.003 \\
\hline $\mathrm{ER}^{+}$ & $46(51.1)$ & $112(62.2)$ & 1.322 & 0.281 \\
\hline $\mathrm{PR}^{+}$ & $42(46.7)$ & $64(35.6)$ & 2.231 & 0.113 \\
\hline
\end{tabular}

*, including medullary carcinoma and apocrine gland carcinoma. 
Table 2 Treatment of patients

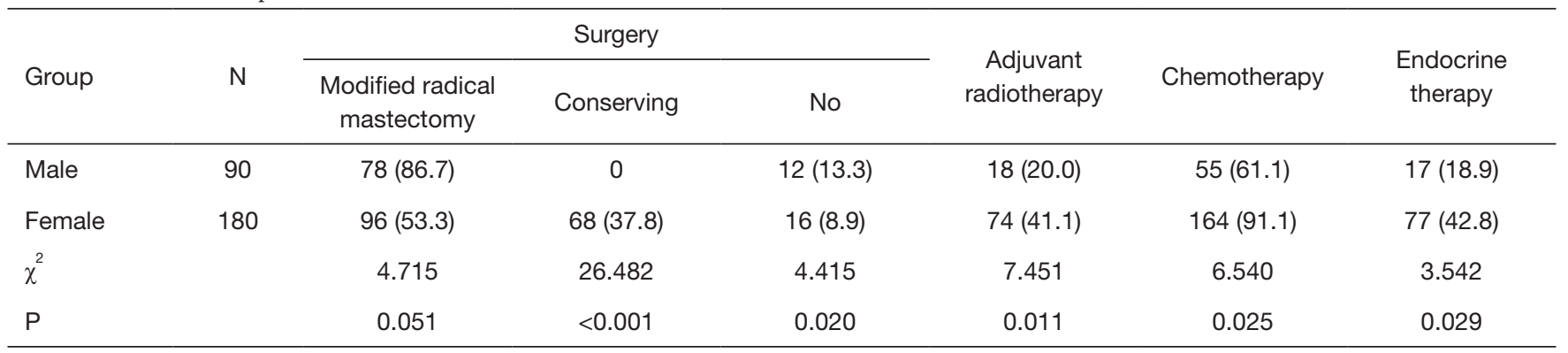

the two groups, such as mass positions, ethnic group and invasive lobular carcinoma.

\section{Treatment of $M B C$ vs. FBC}

For male patients, 78 received modified radical mastectomy and 12 did not receive surgical treatment. Eighteen patients were treated with adjuvant radiotherapy and 55 with chemotherapy including CMF for patients underlying disease. Endocrine therapy was performed on 17 patients including three using letrozole and one with castration plus letrozole. For female patients, 96 received modified radical mastectomy and 68 had conserving surgery. Sixteen did not receive surgical treatment. Chemotherapy was performed on 82 patients including one patient with CMF due to heart disease, 20 with AC-TH and the rest with ACT. Endocrine therapy was used in 62 patients, among them, 46 used tamoxifen, 38 used letrozole and 2 used anastrozole. Analysis of treatments showed that about $87 \%$ of male patients were treated by modified radical mastectomy and the remaining was not treated surgically, while for female patients, both modified radical mastectomy $(53.3 \%)$ and conserving surgery $(37.8 \%)$ were used and only less than $10 \%$ of patients were not surgically treated (Table 2). In addition, less male patients received adjuvant radiotherapy, chemotherapy and endocrine therapy as compared with female patients $(\mathrm{P}<0.05$, Table 2).

\section{Overall survival rate (OSR) and disease-free survival rate (DFSR)}

The OSR and DFSR of patients with BC were $85.4 \%$ and $72.2 \%$, respectively. Among them, the OSR and DFSR of MBC were $68.5 \%$ and $47.9 \%$, respectively, which were significantly lower than those of FBC $(91.7 \%$ and $87.1 \%$, $\chi^{2}=12.335, \mathrm{P}<0.001 ; \chi^{2}=23.453, \mathrm{P}<0.001$, respectively, Figure 1).

\section{Univariate analysis of factors affecting survival}

Univariate analysis of factors influencing the survival of MBC patients showed that T stage, TNM stage, PR status, chemotherapy and endocrine therapy had significant impact on 5-year survival rate in the male patients. Patients at T3 and T4 T stages, III and IV TNM stages, with $\mathrm{PR}^{+}$status, and without chemotherapy and endocrine therapy had significantly lower 5 -year OSR, as compared with patients at Tis, T1 and T2 T stages, 0, I and II TNM stages, with $\mathrm{PR}^{-}$status, and with chemotherapy and endocrine therapy. For female patients, the same risk factors were identified except PR status, which did not impact the survival rate in the female patients (Table 3).

\section{Multivariate analysis of factors affecting survival}

For multivariate analysis, $\mathrm{T}$ stage was assigned to 0 (Tis $+\mathrm{T} 1+\mathrm{T} 2)$ or $1(\mathrm{~T} 3+\mathrm{T} 4)$, TNM stage to $0(0+\mathrm{I}+\mathrm{II})$ or 1 (III $+\mathrm{IV}$ ), ER and PR expressions to 0 (positive) or 1 (negative), endocrine and chemotherapy to 0 (with) or 1 (without), and were used as independent variables to analyze their relationship with survival ( 1 for death, 0 for survival). The results showed that T stage, TNM stage, PR status and endocrine therapy were significant independent factors of the survival in the MBC patients $(\mathrm{P}<0.05)$. For women, these factors were TNM stage, chemotherapy and endocrine therapy $(\mathrm{P}<0.05$, Tables 4,5$)$.

\section{Therapeutic difference between $M B C$ and FBC}

To further assess the different response of $\mathrm{MBC}$ and $\mathrm{FBC}$ to 
A

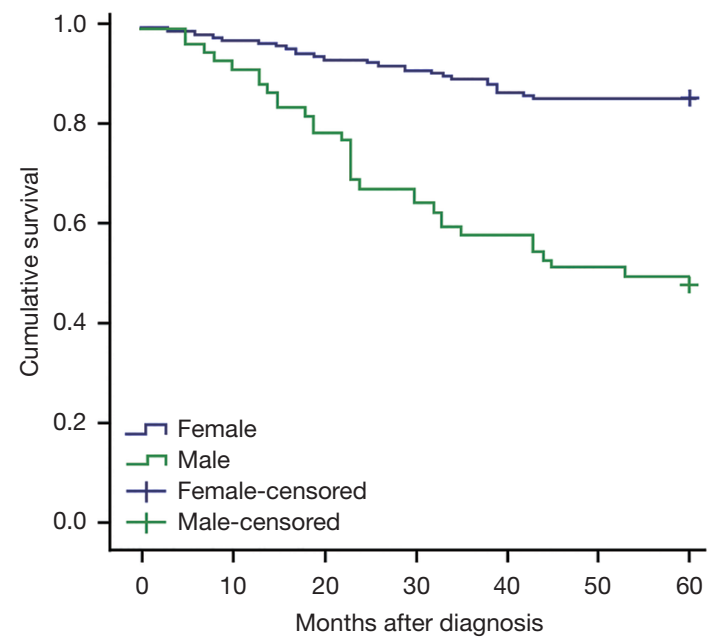

B

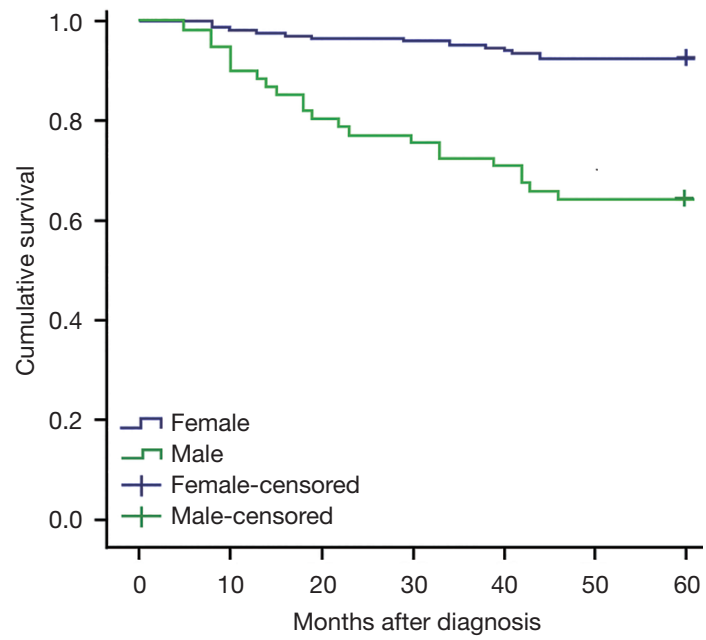

Figure 1 Five-year overall survival rate (A) and disease-free survival rate (B) in male and female breast cancer patients.

Table 3 Univariate analysis of factors affecting 5 -year survival rate in male and female breast cancer patients

\begin{tabular}{|c|c|c|c|c|c|c|}
\hline Variables & \multicolumn{3}{|c|}{ Male } & \multicolumn{3}{|c|}{ Female } \\
\hline T stage & & 19.241 & $<0.001$ & & 18.044 & $<0.001$ \\
\hline Tis $+T_{1}+T_{2}$ & 74.7 & & & 92.1 & & \\
\hline $\mathrm{T}_{3}+\mathrm{T}_{4}$ & 23.9 & & & 70.4 & & \\
\hline $0+I+I I$ & 83.2 & & & 98.7 & & \\
\hline III + IV & 22.7 & & & 78.6 & & \\
\hline ER status & & 2.456 & 0.115 & & 3.441 & 0.051 \\
\hline+ & 64.6 & & & 93.4 & & \\
\hline+ & 71.9 & & & 95.4 & & \\
\hline- & 35.7 & & & 87.2 & & \\
\hline Chemotherapy & & 6.419 & 0.006 & & 11.952 & $<0.001$ \\
\hline Yes & 79.7 & & & 97.1 & & \\
\hline No & 36.3 & & & 70.9 & & \\
\hline Endocrine therapy & & 10.234 & $<0.001$ & & 8.563 & 0.004 \\
\hline Yes & 97.4 & & & 91.5 & & \\
\hline No & 38.5 & & & 82.4 & & \\
\hline
\end{tabular}


Table 4 Multivariate Cox regression analysis for male breast cancer survival

\begin{tabular}{lccccc}
\hline Variable & $\mathrm{B}$ & $\mathrm{SE}$ & Wald $\chi^{2}$ & $\mathrm{P}$ & $\mathrm{HR}(95 \% \mathrm{Cl})$ \\
\hline T stage & -1.279 & 0.290 & 4.211 & 0.015 & $0.218(0.072-0.724)$ \\
TNM stage & -2.338 & 0.439 & 7.345 & 0.016 & $0.102(0.011-0.420)$ \\
ER status & -0.120 & 0.915 & 0.224 & 0.764 & $0.823(0.191-3.123)$ \\
PR status & 1.885 & 0.763 & 9.347 & 0.001 & $6.558(2.953-11.800)$ \\
Chemotherapy & -0.224 & 0.437 & 0.408 & 0.523 & $0.721(0.328-1.954)$ \\
Endocrine therapy & 2.658 & 1.215 & 4.382 & 0.040 & $9.960(1.557-14.260)$ \\
\hline
\end{tabular}

ER, estrogen receptor; PR, progesterone receptor; $\mathrm{HR}$, hazard ratio; $\mathrm{Cl}$, confidence interval.

Table 5 Multivariate Cox regression analysis for female breast cancer survival

\begin{tabular}{lccccc}
\hline Variable & $\mathrm{B}$ & $\mathrm{SE}$ & Wald $\chi^{2}$ & $\mathrm{P}$ & $\mathrm{HR}(95 \% \mathrm{Cl})$ \\
\hline T stage & 1.209 & 0.449 & 0.018 & 0.667 & $1.015(0.323-3.277)$ \\
TNM stage & -2.150 & 0.731 & 9.477 & 0.002 & $0.105(0.045-0.411)$ \\
ER status & 1.337 & 3.252 & 0.132 & 0.773 & $2.208(0.112-7.868)$ \\
PR status & -2.633 & 3.666 & 0.436 & 0.455 & $0.179(0.110-2.799)$ \\
Chemotherapy & 1.871 & 0.585 & 9.226 & 0.001 & $6.496(2.223-18.450)$ \\
Endocrine therapy & 2.600 & 0.707 & 8.113 & 0.004 & $11.433(2.277-29.458)$ \\
\hline
\end{tabular}

$\mathrm{ER}$, estrogen receptor; $\mathrm{PR}$, progesterone receptor; $\mathrm{HR}$, hazard ratio; $\mathrm{Cl}$, confidence interval.

Table 6 Five-year survival rate of MBC and FBC following chemotherapy and endocrine therapy

\begin{tabular}{lccc}
\hline $\begin{array}{l}\text { Cancer } \\
\text { classification }\end{array}$ & $\begin{array}{c}\text { MBC } \\
\text { survival (\%) }\end{array}$ & $\begin{array}{c}\text { FBC } \\
\text { survival (\%) }\end{array}$ & P \\
\hline $\begin{array}{l}\text { TNM stage } \\
\text { III }\end{array}$ & 60.8 & 92.2 & 0.0012 \\
$>$ III & 41.4 & 80.8 & 0.0022 \\
ER/PR status & & & \\
Positive & 73.2 & 93.2 & 0.0211 \\
Negative & 63.2 & 73.2 & 0.0115 \\
\hline
\end{tabular}

$\mathrm{ER}$, estrogen receptor; $\mathrm{PR}$, progesterone receptor; $\mathrm{MBC}$, male breast cancer; FBC, female breast cancer.

therapeutic treatments, we analyzed the survival of patients after endocrine therapy and chemotherapy. The results showed that MBC with $>3$ TNM stage and negative ER/ PR status had poor prognosis as compared with those with $<3$ TNM stage and positive ER/PR status. Meanwhile, with similar TNM stage and ER/PR status, MBC appeared to have poor response to endocrine therapy and chemotherapy with low 5-year survival rate (Table 6).

\section{Discussion}

Our study showed that the median age of male patients was 61 , which is over 10 years older than that of female patients. Compared with female patients, there were more patients aged $\geq 70$ years and having underlying diseases. OSR and DFSR were significantly lower in patients with MBC than with FBC; T stage, TNM stage, PR status and endocrine therapy are found to be independent factors affecting the survival of MBC.

$\mathrm{BC}$ is the most common malignant tumor in women, but it is relatively rare in male (1). Because of this, the cohort of MBC in this study includes near $90 \%$ of all MBC diagnosed at our centers during the study period, while $\mathrm{FBC}$ is only a small portion of FBC patients treated at the same period. Previous studies show that the incidence of $\mathrm{MBC}$ is usually 5 to 10 years later than $\mathrm{FBC}$ and peaks around $68-71$ years old, and MBC patients often have more underlying diseases 
$(32,33)$ and family history of BC (34). These are consistent with our results. Partially due to older age, the male patients were less proactive and more reluctant to treatments, leading to less patients to receive adjuvant radiotherapy, chemotherapy and endocrine therapy as compared with female patients. In addition, drugs for endocrine therapy such as tamoxifen for MBC have side effects such as hot flashes, changes in vision, cognitive changes, and a lower sex drive (35), which might also result in low treatment rates in the male patients.

Understand the pathological type of cancer is important for therapeutic planning. Korde et al. showed that the main pathological type of both $\mathrm{MBC}$ and $\mathrm{FBC}$ is nonspecific invasive ductal carcinoma (36), and Ottini et al. found the invasive ductal carcinoma accounts for $87 \%$ of MBC (37). In this cohort, most of MBC also had invasive ductal carcinoma with a small proportion of ductal carcinoma in situ (DCIS). Although modified radical mastectomy was used for both MBC and FBC (38), more women have adapted breast-conserving surgery due to aesthetic and health considerations and advances in radiotherapy technology, particularly for women with early BC (39). However, over $10 \% \mathrm{MBC}$ patients declined surgical treatment in our study. In man, there is no enough gland tissue to delay the infiltration of the tumor to the surrounding area, leading to invasion of the pectoralis major muscle and skin (40). In addition, MBC is often located in the areola area, making it inappropriate to treat using conserving surgery. Due to less glandular tissue, the nipple or local skin are often invaded by $\mathrm{MBC}$, leading to more radiotherapy after surgery (41). However, in this study, most patients who treated with modified radical mastectomy were treated with adjuvant radiotherapy, likely due to their older age and comorbidities.

BC ranks the first in the major malignant tumors in our hospitals. The 5 -year OSR is $84.23 \%$, which is higher than what are reported for other regions such as Shanghai and Zhejiang (42). In this study, the 5-year OSR was $85.4 \%$, which is similar to the results of previous studies (42), and the OSR and DFSR of MBC are lower than those of FBC in the same period $(\mathrm{P}<0.05)$, which is similar to the conclusion of earlier studies $(4,43)$. However, the OSR and DFSR of MBC are lower than those reported outside China (23) and higher than those reported inside China (44), suggesting that the survival rate is likely linked to the medical levels in addition to the biological features of the disease.

The results of this study showed that T stage, TNM stage, endocrine therapy are significant prognostic factors for MBC and FBC. This is consistent with most previous studies (45). In this study, male patients had more luminal type as compared with female patients, which is consistent with previous findings (4). Based on SEER database, it was found that the death rate had reduced by $42 \%$ in female but only $28 \%$ in male between 1996 and 2005, duo to wide-spread use of endocrine therapy. However, endocrine therapy is less adapted in male patients. It is likely due to severe adverse reactions and poor compliance to endocrine therapy in male patients (46).

Since BC is highly heterogeneous (47), molecular typing has been widely used to characterize its biological features and augment traditional methods to improve our understanding of $\mathrm{BC}$ and their clinical management $(48,49)$. During the last 20 years, five intrinsic molecular subtypes (luminal A, luminal B, HER-2-enriched, basal-like and claudin-low) have been identified for BC and have been lined to therapeutic outcomes for female patients as well as for $\mathrm{MBC}(50)$. For example, $\mathrm{ER}^{+} / \mathrm{PR}^{+} \mathrm{MBC}$ patients were found to have lower survival rate than $\mathrm{ER}^{+} / \mathrm{PR}^{-}$patients (51) and patients with HER-2 ${ }^{+} / \mathrm{HER}-2$-enriched disease is likely to benefit the most from neoadjuvant trastuzumab (50). In this study, we also found that PR status is an independent risk factors for survival, and $\mathrm{PR}^{-}$patients have high death risk (HR 6.5) for MBC, ER status is significantly related to the survival in FBC but not in MBC. This is different from the previous study based on SEER Database (25). In addition, although chemotherapy is a prognostic factor for $\mathrm{FBC}$, it does not significantly impact the OSR of MBC patients in this study. This is likely because chemotherapy has greater side reactions in male patients, who are older and have more underlying diseases, leading to poor tolerant and subsequently poor outcomes.

There are limitations of this study, including small sample size, partially due to low incidence rate of $\mathrm{MBC}$ and single-center study. Female patients were randomly drawn from a large patient pool, which may have bias for characterizing the clinical features of patients. The following up time was short, particularly for lately enrolled patients. In addition, BRCA2 germline mutations and DNA-repair genes such as CHEK2 and PALB2 have been shown to be a major risk factor for MBC (4) but were not available for analysis in this study.

\section{Conclusions}

Although MBC seems globally similar to FBC, it has distinct features, such as older on-set age, high portion of 
luminal cells and more comorbidities. MBC is more related to family history of cancer and has low OSR and DFSR as compared with FBC. T stage, TNM stage, PR status and endocrine therapy were independent prognostic factors for survival of MBC.

\section{Acknowledgments}

Funding: None.

\section{Footnote}

Reporting Checklist: The authors have completed the STROBE reporting checklist. Available at http://dx.doi. org/10.21037/tcr-21-1

Data Sharing Statement: Available at http://dx.doi. org/10.21037/tcr-21-1

Peer Review File: Available at http://dx.doi.org/10.21037/tcr21-1

Conflicts of Interest: All authors have completed the ICMJE uniform disclosure form (available at http://dx.doi. org/10.21037/tcr-21-1). The authors have no conflicts of interest to declare.

Ethical Statement: The authors are accountable for all aspects of the work in ensuring that questions related to the accuracy or integrity of any part of the work are appropriately investigated and resolved. This study was approved by the Ethics Committee of Nanjing Medical University (approval No.: NMU 2719-3), conducted in accordance with the Declaration of Helsinki (as revised in 2013) and written informed consent was obtained from every participant.

Open Access Statement: This is an Open Access article distributed in accordance with the Creative Commons Attribution-NonCommercial-NoDerivs 4.0 International License (CC BY-NC-ND 4.0), which permits the noncommercial replication and distribution of the article with the strict proviso that no changes or edits are made and the original work is properly cited (including links to both the formal publication through the relevant DOI and the license). See: https://creativecommons.org/licenses/by-nc-nd/4.0/.

\section{References}

1. Siegel RL, Miller KD, Jemal A. Cancer statistics, 2020. CA Cancer J Clin 2020;70:7-30.

2. Serdy KM, Leone JP, Dabbs DJ, et al. Male Breast Cancer. Am J Clin Pathol 2017;147:110-9.

3. Chen $W$, Zheng R, Baade PD, et al. Cancer statistics in China, 2015. CA Cancer J Clin 2016;66:115-32.

4. Gucalp A, Traina TA, Eisner JR, et al. Male breast cancer: a disease distinct from female breast cancer. Breast Cancer Res Treat 2019;173:37-48.

5. Fentiman IS. Male breast cancer is not congruent with the female disease. Crit Rev Oncol Hematol 2016;101:119-24.

6. Cardoso F, Bartlett JMS, Slaets L, et al. Characterization of male breast cancer: results of the EORTC 10085/ TBCRC/BIG/NABCG International Male Breast Cancer Program. Ann Oncol 2018;29:405-17.

7. Cutuli B. Strategies in treating male breast cancer. Expert Opin Pharmacother 2007;8:193-202.

8. Li X, Yang J, Krishnamurti U, et al. Hormone ReceptorPositive Breast Cancer Has a Worse Prognosis in Male Than in Female Patients. Clin Breast Cancer 2017;17:356-66.

9. Leone J, Zwenger AO, Leone BA, et al. Overall Survival of Men and Women With Breast Cancer According to Tumor Subtype: A Population-based Study. Am J Clin Oncol 2019;42:215-20.

10. Wang K, Wang QJ, Xiong YF, et al. Survival Comparisons Between Early Male and Female Breast Cancer Patients. Sci Rep 2018;8:8900.

11. Ozkurt E, Tukenmez M, Yilmaz R, et al. Favorable LongTerm Outcome in Male Breast Cancer. Eur J Breast Health 2018;14:180-5.

12. Abdelwahab Yousef AJ. Male Breast Cancer: Epidemiology and Risk Factors. Semin Oncol 2017;44:267-72.

13. Massarweh SA, Choi GL. Special considerations in the evaluation and management of breast cancer in men. Curr Probl Cancer 2016;40:163-71.

14. Ottini L. Male breast cancer: a rare disease that might uncover underlying pathways of breast cancer. Nat Rev Cancer 2014;14:643.

15. Hanoteau A, Newton JM, Krupar R, et al. Tumor microenvironment modulation enhances immunologic benefit of chemoradiotherapy. J Immunother Cancer 2019;7:10.

16. Xiong Z, Deng G, Huang X, et al. Score for the Survival 
Probability in Metastasis Breast Cancer: A NomogramBased Risk Assessment Model. Cancer Res Treat 2018;50:1260-9.

17. Sun YS, Zhao Z, Yang ZN, et al. Risk Factors and Preventions of Breast Cancer. Int J Biol Sci 2017;13:1387-97.

18. Geng SK, Fu SM, Fu YP, et al. Neutrophil to lymphocyte ratio is a prognostic factor for disease free survival in patients with breast cancer underwent curative resection. Medicine (Baltimore) 2018;97:e11898.

19. Zeindler J, Angehrn F, Droeser R, et al. Infiltration by myeloperoxidase-positive neutrophils is an independent prognostic factor in breast cancer. Breast Cancer Res Treat 2019;177:581-9.

20. Renda I, Bianchi S, Vezzosi V, et al. Expression of FGD3 gene as prognostic factor in young breast cancer patients. Sci Rep 2019;9:15204.

21. Rakha EA, Reis-Filho JS, Baehner F, et al. Breast cancer prognostic classification in the molecular era: the role of histological grade. Breast Cancer Res 2010;12:207.

22. Zhao S, Ma D, Xiao Y, et al. Clinicopathologic features and prognoses of different histologic types of triplenegative breast cancer: A large population-based analysis. Eur J Surg Oncol 2018;44:420-8.

23. Masci G, Caruso M, Caruso F, et al. Clinicopathological and Immunohistochemical Characteristics in Male Breast Cancer: A Retrospective Case Series. Oncologist 2015;20:586-92.

24. Ferzoco RM, Ruddy KJ. The Epidemiology of Male Breast Cancer. Curr Oncol Rep 2016;18:1.

25. Chen S, Liu Y, Yang J, et al. Development and Validation of a Nomogram for Predicting Survival in Male Patients with Breast Cancer. Front Oncol 2019;9:361.

26. Leon-Ferre RA, Giridhar KV, Hieken TJ, et al. A contemporary review of male breast cancer: current evidence and unanswered questions. Cancer Metastasis Rev 2018;37:599-614.

27. Lautrup MD, Thorup SS, Jensen V, et al. Male breast cancer: a nation-wide population-based comparison with female breast cancer. Acta Oncol 2018;57:613-21.

28. Amin MB, Greene FL, Edge SB, et al. The Eighth Edition AJCC Cancer Staging Manual: Continuing to build a bridge from a population-based to a more "personalized" approach to cancer staging. CA Cancer J Clin 2017;67:93-9.

29. Daly MB, Pilarski R, Yurgelun MB, et al. NCCN Guidelines Insights: Genetic/Familial High-Risk Assessment: Breast, Ovarian, and Pancreatic, Version
1.2020. J Natl Compr Canc Netw 2020;18:380-91.

30. Fisher B, Jeong JH, Anderson S, et al. Twenty-fiveyear follow-up of a randomized trial comparing radical mastectomy, total mastectomy, and total mastectomy followed by irradiation. N Engl J Med 2002;347:567-75.

31. Scott-Conner CE, Jochimsen PR, Menck HR, et al. An analysis of male and female breast cancer treatment and survival among demographically identical pairs of patients. Surgery 1999;126:775-80; discussion 780-1.

32. Ferzoco RM, Ruddy KJ. Optimal delivery of male breast cancer follow-up care: improving outcomes. Breast Cancer (Dove Med Press) 2015;7:371-9.

33. Gao Y, Heller SL, Moy L. Male Breast Cancer in the Age of Genetic Testing: An Opportunity for Early Detection, Tailored Therapy, and Surveillance. Radiographics 2018;38:1289-311.

34. Rudlowski C. Male Breast Cancer. Breast Care (Basel) 2008;3:183-9.

35. Kiluk JV, Lee MC, Park CK, et al. Male breast cancer: management and follow-up recommendations. Breast J 2011;17:503-9.

36. Korde LA, Zujewski JA, Kamin L, et al. Multidisciplinary meeting on male breast cancer: summary and research recommendations. J Clin Oncol 2010;28:2114-22.

37. Ottini L, Silvestri V, Rizzolo P, et al. Clinical and pathologic characteristics of BRCA-positive and BRCAnegative male breast cancer patients: results from a collaborative multicenter study in Italy. Breast Cancer Res Treat 2012;134:411-8.

38. Losurdo A, Rota S, Gullo G, et al. Controversies in clinicopathological characteristics and treatment strategies of male breast cancer: A review of the literature. Crit Rev Oncol Hematol 2017;113:283-91.

39. Hassan Ali S, S P S, N AK. Rate of Breast-Conserving Surgery vs Mastectomy in Breast Cancer: a Tertiary Care Centre Experience from South India. Indian J Surg Oncol 2019;10:72-6.

40. Serarslan A, Gursel B, Okumus NO, et al. Male Breast Cancer: 20 Years Experience of a Tertiary Hospital from the Middle Black Sea Region of Turkey. Asian Pac J Cancer Prev 2015;16:6673-9.

41. Yu E, Suzuki H, Younus J, et al. The impact of postmastectomy radiation therapy on male breast cancer patients--a case series. Int J Radiat Oncol Biol Phys 2012;82:696-700.

42. Fan L, Strasser-Weippl K, Li JJ, et al. Breast cancer in China. Lancet Oncol 2014;15:e279-89.

43. Wu Q, Li J, Zhu S, et al. Poorer breast cancer survival 
outcomes in males than females might be attributable to tumor subtype. Oncotarget 2016;7:87532-42.

44. Huang Z, Wen $W$, Zheng $Y$, et al. Breast cancer incidence and mortality: trends over 40 years among women in Shanghai, China. Ann Oncol 2016;27:1129-34.

45. Choi MY, Lee SK, Lee JE, et al. Characterization of Korean Male Breast Cancer Using an Online Nationwide Breast-Cancer Database: Matched-Pair Analysis of Patients With Female Breast Cancer. Medicine (Baltimore) 2016;95:e3299.

46. Kwong A, Chau WW, Mang OW, et al. Male breast cancer: a population-based comparison with female breast cancer in Hong Kong, Southern China: 1997-2006. Ann Surg Oncol 2014;21:1246-53.

Cite this article as: Sang G, Pan H, Lu C, Sun R, Zha X, Wang S, Zhu D. Clinical features and prognostic factors of male breast cancer vs. female breast cancer. Transl Cancer Res 2021;10(5):2199-2209. doi: 10.21037/tcr-21-1
47. Simpson PT, Reis-Filho JS, Lakhani SR. Breast pathology: beyond morphology. Semin Diagn Pathol 2010;27:91-6.

48. Provenzano E, Ulaner GA, Chin SF. Molecular Classification of Breast Cancer. PET Clin 2018;13:325-38.

49. Merino Bonilla JA, Torres Tabanera M, Ros Mendoza LH. Breast cancer in the 21st century: from early detection to new therapies. Radiologia 2017;59:368-79.

50. Prat A, Pineda E, Adamo B, et al. Clinical implications of the intrinsic molecular subtypes of breast cancer. Breast 2015;24 Suppl 2:S26-35.

51. Wei JL, Zhang JX, Fu DY. Characterization and prognosis of estrogen receptor-positive/progesterone receptornegative male breast cancer: a population-based study. World J Surg Oncol 2018;16:236. 